\title{
Repeat corneal graft failure due to graft-to-host herpetic infection
}

\author{
Zisis Gatzioufas ${ }^{1 *}$, Andrea Hasenfus ${ }^{2}$, Balasz Gyongyossy ${ }^{1}$, Evangelos Stavridis ${ }^{1}$, Marlies Sauter ${ }^{3}$, Sigrun Smola ${ }^{3}$ \\ and Berthold Seitz ${ }^{1}$
}

\begin{abstract}
Background: Herein, we present the case of a young female patient with keratoconus, who was subjected twice to repeat keratoplasty, and each time, she experienced a corneal graft failure.

Findings: Under the suspicion of herpetic eye disease, we administered topical and systemic anti-herpetic treatment after the second repeat keratoplasty. The postoperative course was uneventful, and the corneal graft is clear, until recently. Immunohistochemistry and DNA-polymerase chain reaction were negative for herpes simplex virus-1 (HSV-1) in the host cornea, but they detected HSV-1 in both transplanted corneal grafts, thereby supporting our clinical hypothesis that graft-to-host HSV-1 infection elicited this chain reaction of complications in our patient.

Conclusion: This clinical report illustrates in a unique way the dramatic impact an unsuspected herpetic infection in the corneal graft in cases of keratoplasty may have and underscores the necessity of suspecting and adequately treating these distinct cases.
\end{abstract}

Keywords: Penetrating keratoplasty, Herpes simplex virus, HSV, Corneal graft failure, DNA-PCR, Immunohistochemistry

\section{Findings}

Introduction

Several authors have reported the occurrence of herpetic keratitis after penetrating keratoplasty in patients with no history of herpetic disease [1-3]. It has been hypothesized that graft-to-host transmission of herpes simplex virus 1 (HSV-1) may cause herpetic keratitis, which is described as 'newly acquired' keratitis [2,4]. However, reactivation of a latent HSV-1 infection may also account for persisting corneal epithelial defects or even corneal graft failure after penetrating keratoplasty [5]. Hereby, we present a unique case of repeat corneal graft failure after penetrating keratoplasty, which is associated with graft-to-host HSV-1 infection.

\section{Case report}

A 45-year-old female patient presented in our outpatient clinic in June 2008, complaining of gradual deterioration of visual acuity in the left eye (OS) for 1 year. She had no medical history and received no medication. Best-corrected

\footnotetext{
* Correspondence: zisis.gkatzioufas@uks.eu

${ }^{1}$ Department of Ophthalmology, University of Saarland, Kirrberger Str,

Homburg/Saar, Saarland 66424, Germany

Full list of author information is available at the end of the article
}

visual acuity (BCVA) was $9 / 10$ in the right eye (OD) and $1 / 20$ OS. Intraocular pressure (IOP) was $14 \mathrm{mmHg}$ OD and $15 \mathrm{mmHg}$ OS. Objective refraction was $+2.5 /-1.25 / 55^{\circ}$ OD and $+1.5 /-2.25 / 45^{\circ}$ OS. Slit-lamp examination revealed central corneal irregularity with marked thinning of the paracentral cornea OS (Figure 1A). Scheimpflug examination confirmed this finding (central corneal thickness OS, $482 \mu \mathrm{m}$ ), and a clinical diagnosis of keratoconus was made. After a thorough explanatory conversation, we recommended a penetrating excimer laser-assisted keratoplasty (PKP) OS, and the patient was enrolled on our waiting list.

In December 2008, the patient underwent an uneventful PKP OS. Because of a persisting epithelial defect postoperatively and despite topical treatment with autologous serum, the patient was subjected to amniotic membrane transplantation 2 weeks later. She was discharged with a bandage contact lens and prednisolone eye drops three times a day, ofloxacin eye drops five times a day and artificial tear drops five times a day. BCVA was 10/10 OD and $1 / 25$ OS.

In June 2009, the patient referred to our clinic for regular follow-up examination. Slit-lamp examination revealed a diffuse cloudiness of the corneal graft due to the integrated amniotic membrane, with stromal oedema and multiple 

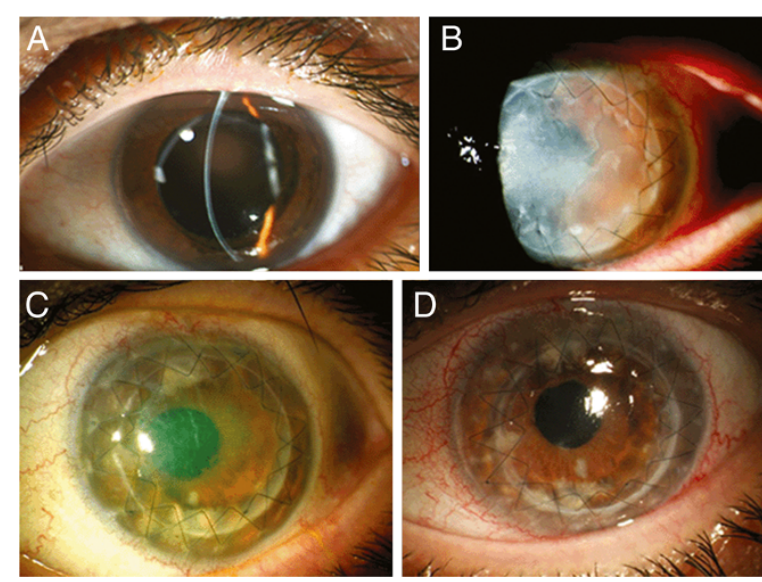

Figure 1 Slit-lamp examination of the left eye. (A) Corneal irregularity with marked thinning of the central cornea is observed in June 2008. (B) Slit-lamp examination of the left eye after penetrating keratoplasty revealed a diffuse cloudiness of the corneal graft with stromal oedema (June 2009). (C) Slit-lamp examination of the left eye in November 2009 showed an epithelial defect on the central cornea, which did not heal despite intensive topical therapy with autologous serum. (D) The corneal graft is clear after the second repeat keratoplasty, and there are no signs of infection (February 2011).

Descemet membrane folds (Figure 1B) [6,7]. Since the graft had never been clear after PKP, the diagnosis of primary graft failure was made, and an intensive treatment with corticosteroids was administered (prednisolone eye drops hourly, prednisolone $250 \mathrm{mg}$ intravenously for 3 days on a tapering dose). Despite topical and systemic cortisone therapy, we did not observe a clinical improvement, and the patient was included in our waiting list for a repeat keratoplasty OS. BCVA was 10/10 OD and hand movement OS.

In July 2009, the patient underwent an uneventful repeat PKP OS. On postoperative day 7, the corneal epithelium was healed, and the patient was discharged on a tapering dose of topical corticosteroids (prednisolone eye drops eight times a day, ofloxacin eye drops four times a day for a week, dexpanthenol eye gel five times a day). BCVA was 09/10 OD and 1/20 OS. IOP was $17 \mathrm{mmHg}$ OD and $16 \mathrm{mmHg}$ OS. Follow-up examination was planned in 8 weeks. After 2 weeks, the patient was referred to our emergency clinic with elevation of the IOP OS. IOP was $19 \mathrm{mmHg}$ OD and $31 \mathrm{mmHg}$ OS. Under topical therapy, the IOP was normalized, and upon suspicion of steroid response, the patient was discharged with rimexolone eye drops four times a day, dexpanthenol five times a day and a fixed combination of brimonidine/timolol two times a day. BCVA was 9/10 OD and 4/10 OS.

In November 2009, the patient presented in our clinic with a persisting epithelial defect OS, which did not heal despite intensive topical therapy with autologous serum (Figure 1C). In December 2009, an amniotic membrane transplantation was performed OS. After 4 weeks, the epithelial defect was healed, and BCVA was 1/10 OS.

In October 2010, the patient presented with ocular pain OS. BCVA was 10/10 OD and 1/10 OS. Slit-lamp examination revealed diffuse haze of the corneal graft with prominent stromal oedema due to endothelial decompensation. Anterior chamber examination showed 1+ cells, and no Khodadoust line was observed. IOP was $18 \mathrm{mmHg}$ OD and $36 \mathrm{mmHg}$ OS. The diagnosis of chronic diffuse endothelial graft failure was made, and the patient was commenced on intensive topical and systemic treatment with corticosteroids (prednisolone eye drops hourly, prednisolone $250 \mathrm{mg}$ intravenous for 3 days on a tapering dose). After 1 week, the patient was discharged with prednisolone eye drops eight times a day (on a tapering dose), dexpanthenol five times a day, a fixed combination brimonidine/timolol two times a day and methylprednisolone $80 \mathrm{mg}$ per OS daily (on tapering dose). Nonetheless, clinical findings OS did not improve significantly, and the decision for a second repeat PKP was made.

In November 2010, the patient underwent a re-repeat PKP for chronic diffuse endothelial graft failure OS. BCVA was $10 / 10$ OD and $1 / 10$ OS. IOP was $15 \mathrm{mmHg}$ OD and $17 \mathrm{mmHg}$ OS. Under the suspicion of herpetic eye disease, we administered, in addition to the usual post-keratoplasty therapy, topical and systemic anti-herpetic treatment (acyclovir $400 \mathrm{mg}$ five times a day for 4 weeks and afterwards two times a day for 12 months, ganciclovir eye gel once a day). Immunohistochemical analysis of the native host cornea was negative for HSV-1 (Figure 2). Polymerase chain reaction (PCR) confirmed the absence of HSV-1 in the host cornea. However, immunohistochemical and PCR analyses of both the first and second corneal graft were positive for HSV-1 (Figure 2). The sensitivity of the applied PCR technique was very high (approximately 98\%). The viral load in the first corneal graft was $4 \times 10^{3}$ copies $/ \mathrm{mL}$, and the viral load in the second corneal graft was $6 \times 10^{6}$ copies $/ \mathrm{mL}$. The postoperative course after the re-repeat PKP was excellent under systemic anti-herpetic treatment, and the corneal graft is clear, until recently (Figure 1D).

\section{Discussion}

Biswas et al. were the first to describe the clinical hypothesis of graft-to-host transmission of HSV-1 [8]. Later on, Remeijer et al. presented clinical data supporting this clinical scenario [9]. Jhanji et al. have recently reported an interesting case series of patients with 'new-onset' herpetic eye disease after ocular surgery, suggesting that graft-to-host transmission of HSV-1 may have occurred [4]. However, the clinical impact of graft-to-host herpetic infection is controversial, based on the fact that such a clinical scenario is a rare phenomenon [10]. 


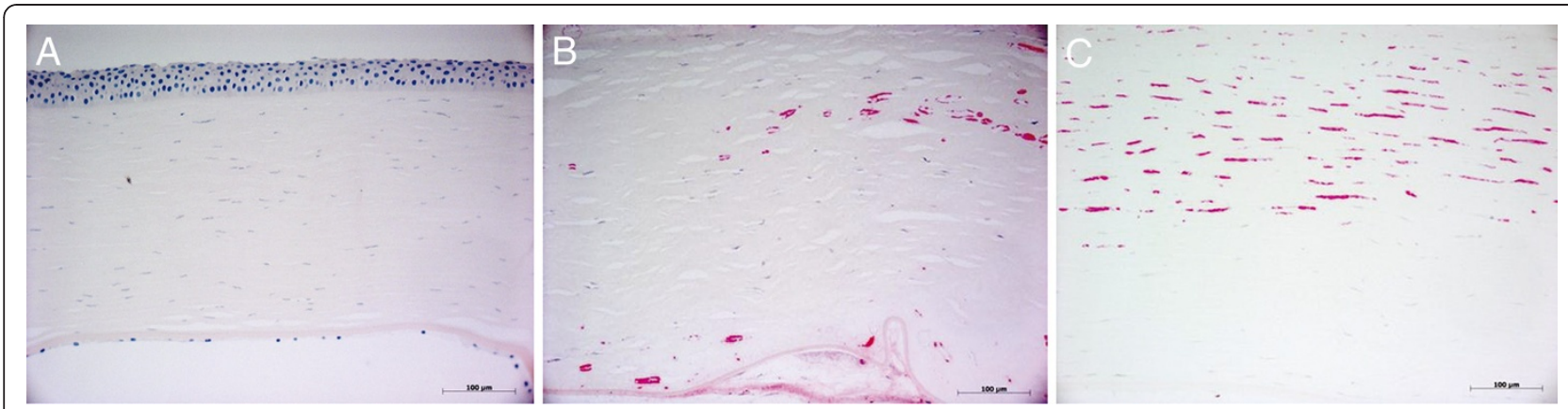

Figure 2 Immunohistochemical analysis of the host cornea. (A) Immunohistochemical analysis of the host cornea for herpes simplex virus 1 (HSV-1) was negative (X20). (B) Immunohistochemical examination of the first corneal graft (after the first repeat keratoplasty) showed a strong signal for HSV-1 (×20). (C) Immunohistochemical analysis of the second corneal graft (after the second repeat keratoplasty) also revealed a strong signal for HSV-1 $(\times 20)$. Scale bar $=100 \mu \mathrm{m}$.

Our patient had no history of herpetic eye disease. When evaluating the entire clinical course of this case, our patient suffered postoperatively from persisting corneal epithelial defects due to impaired corneal re-epithelialization and experienced one episode of keratouveitis as well as two corneal graft failures. The common etiological factor inducing this chain reaction of 'unexplained clinical pitfalls' could have been HSV-1 since the herpetic eye disease is a chameleon regarding the vast variety of clinical expressions and manifestations [5]. Indeed, immunohistochemical analysis and PCR confirmed the presence of HSV-1 in both corneal grafts, but not in the host cornea, thereby supporting our clinical hypothesis that graft-to-host ping-pong HSV-1 infection elicited this chain reaction of complications in our patient. Unfortunately, the corneoscleral ring of the donor tissue was no longer available for HSV DNAPCR in this patient. Therefore, we cannot definitely exclude a host-derived source of the HSV-1 infection. On the other hand, the second corneal graft may have been salvaged when the patient developed corneal graft haze and IOP elevation if we had performed PCR analysis of an aqueous humour sample for HSV or other viruses, which is an easy, rapid and sensitive method for the confirmation of HSV infection [11]. Instead, the patient was treated more intensively with topical and systemic steroids, which may have potentially aggravated the HSV infection and accelerated the corneal graft failure.

Our clinical suspicion of 'herpetic eye disease' was rather delayed, and our patient experienced the dramatic consequences of an untreated herpetic infection in the postkeratoplasty period. This clinical report illustrates in a unique way the dramatic impact an unsuspected herpetic infection on the corneal graft in cases of keratoplasty may have and underscores the necessity of suspecting and adequately treating these distinct cases. The application of aqueous humour analysis either by PCR or by GoldmannWitmer coefficient analysis for early diagnosis of HSV infection may be of paramount clinical importance in such distinct cases.

All investigations performed in the manuscript were in compliance with the Helsinki Declaration and approved by the Ethics Committee of the University of Saarland/ Germany. Written informed consent was obtained from the patient for publication of this report and any accompanying images.

\section{Conclusion}

In conclusion, it is advisable to perform analysis of an aqueous humour sample for detection of potential viral infection in patients with clinically suspected HSV infection after PKP in order to treat early this condition and increase the chances of corneal graft survival.

\section{Competing interests}

The authors declare that they have no competing interests.

\section{Authors' contributions}

ZG coordinated the study and drafted the manuscript. AH carried out the immunohistochemical examinations. BG participated in the patient examination and follow-up. MS carried out the PCR experiments. SS participated in the PCR experiments and made a critical revision of the manuscript. ES participated in the patient follow-up and provided the slitlamp photos. BS performed all surgical procedures and made a critical revision of the manuscript. All authors read and approved the final manuscript.

\section{Author details}

${ }^{1}$ Department of Ophthalmology, University of Saarland, Kirrberger Str, Homburg/Saar, Saarland 66424, Germany. '2Department of Pathology, University of Saarland, Homburg/Saar 66424, Germany. ${ }^{3}$ Institute of Virology, University of Saarland, Homburg/Saar 66424, Germany.

Received: 10 September 2012 Accepted: 12 September 2012 Published: 28 January 2013

\section{References}

1. Mannis MJ, Plotnik RD, Schwab IR, Newton RD (1991) Herpes simplex dendritic keratitis after keratoplasty. Am J Ophthalmol 111:480-484

2. Remeijer L, Doornenbal P, Geerards AJ, Rijneveld WA, Beekhuis WH (1997) Newly acquired herpes simplex virus keratitis after penetrating keratoplasty. Ophthalmology 104:648-652 
3. Borderie VM, Meritet JF, Chaumeil C, Rozenberg F, Baudrimont M, Touzeau O, Bourcier T, Laroche L (2004) Culture proven herpetic keratitis after penetrating keratoplasty in patients with no previous history of herpes disease. Cornea 23:118-124

4. Jhanji V, Ferdinands M, Sheorey H, Sharma N, Jardine D, Vajpayee R (2011) Unusual clinical presentations of new-onset herpetic eye disease after ocular surgery. Acta Ophthalmol 89:e474-e475

5. Seitz B, Heiligenhaus A (2011) Herpetic keratitis. Various expressions require different therapeutic approaches Ophthalmologe 108:385-395

6. Resch MD, Schlötzer-Schrehardt U, Hofmann-Rummelt C, Sauer R, Kruse FE, Beckmann MW, Seitz B (2006) Integration patterns of cryopreserved amniotic membranes into the human cornea. Ophthalmology 113:1927-1935

7. Seitz B, Resch MD, Schlötzer-Schrehardt U, Hofmann-Rummelt C, Sauer R, Kruse FE (2006) Histopathology and ultrastructure of human corneas after amniotic membrane transplantation. Arch Ophthalmol 124:1487-1490

8. Biswas S, Suresh P, Bonshek R, Corbitt G, Tullo AB, Ridgway AE (2000) Graft failure in human donor corneas due to transmission of herpes simplex virus. Br J Ophthalmol 84:701-705

9. Remeijer L, Maertzdorf J, Doornenbal P, Verjans GM, Osterhaus AD (2001) Herpes simplex virus 1 transmission through corneal transplantation. Lancet 357:442

10. Remeijer L, Duan R, van Dun JM, Wefers Bettink MA, Osterhaus AD, Verjans GM (2009) Prevalence and clinical consequences of herpes simplex virus type 1 DNA in human corneal tissues. J Infect Dis 200:11-19

11. Fox GM, Crouse CA, Chuang EL, Pflugfelder SC, Cleary TJ, Nelson SJ, Atherton SS (1991) Detection of herpesvirus DNA in vitreous and aqueous specimens by the polymerase chain reaction. Arch Ophthalmol 109:266-271

doi:10.1186/1869-5760-3-24

Cite this article as: Gatzioufas et al:: Repeat corneal graft failure due to graft-to-host herpetic infection. Journal of Ophthalmic Inflammation and Infection 2013 3:24.

\section{Submit your manuscript to a SpringerOpen ${ }^{\circ}$ journal and benefit from:}

- Convenient online submission

- Rigorous peer review

- Immediate publication on acceptance

Open access: articles freely available online

- High visibility within the field

- Retaining the copyright to your article

Submit your next manuscript at $\gg$ springeropen.com 